\title{
Calculating the medical time required in the psychiatry of mental handicap
}

\author{
J. Piachaud, Consultant Psychiatrist in Mental Handicap and Honorary Senior \\ Lecturer, St Mary's Hospital Medical School (address for correspondence: Paddington \\ Community Hospital, 7a Woodfield Road, London W9 2BB)
}

A method for estimating the psychiatric manpower needs of a district has been described in the Bulletin (Watson, 1986), and while the data presented in that article were for general psychiatry the approach to this issue can be modified for specialist services.

In this report estimates of time required for items of medical activity in the psychiatry of mental handicap were gathered from 13 consultants, including members of the Mental Handicap Executive Committee. Other data concerning patterns of clinical practice were also collected.

\section{The study}

To gather this opinion a questionnaire was devised defining a number of medical activities. These fell broadly into:

(a) activities springing directly from patient contact (all doctors), e.g. in-patients, out-patients, day-patients

(b) indirect clinical time (all doctors), e.g. regular clinical discussion with other professionals, ward rounds and case conferences

(c) time spent on non-clinical activity (consultants only), e.g. administration, management, teaching.

Consultants were asked to give estimates of times required to perform these activities.

The activities around direct patient contact were split into face to face contact and work immediately generated by this, e.g. letters, phone calls, meeting direct care staff/parents. This latter work was termed para-patient activity (Watson, 1986) and was sought separately.

The questionnaire also addressed some service design issues (e.g. catchment population, designations of beds, number of out-patients). Respondents were also asked to estimate the ideal number of in-patient and day-patient facilities required for their catchment population.

\section{Findings}

The answers showed great variance and skewed distribution, therefore the median was taken as the mid- point estimate of the various scores (except for the number of day places where a mean was used). Where there were tied medians these were averaged.

Where respondents indicated part-time appointments the indirect clinical activity was increased on a pro-rata basis.

Direct patient contact The times given in Table I include both face to face and para-patient activity.

Table II gives information about numbers of inpatient, out-patient and day-patient places. By combining the information in Table I with Table II the routine medical time required each week in each of these areas of service can be calculated:

\begin{tabular}{lccc}
\hline & Number & Time/item/week & Time/week \\
IP & $20(1)$ & 60 minutes & 1200 minutes \\
OP new & 1.25 & 105 & 131.25 \\
OP old & 5.75 & 45 & 258.75 \\
DP & 7 & 20 & 140 \\
Long-stay & $100(2)$ & 12 & 1200 \\
Direct patient contacts: & & 2930 minutes/ \\
& & & per week (3)
\end{tabular}

(1) This figure includes those beds designated psychiatric assessment and rehabilitation.

(2) This figure is all those beds not in (1).

(3) The calculations do not include time for new admissions, emergencies and a range of other activities which are discussed later on.

Indirect clinical times: The median scores of the various activities were added together, giving a weekly total for one doctor. As many activities (e.g. ward rounds, case conferences) would involve a consultant and junior staff, an additional element is required to allow for the presence of two doctors.
Clinical discussions:
869 minutes
Additional time for two doctors: $\quad 629$ minutes Indirect clinical time:
1490 minutes/week.

Non clinical time: The median scores for the various activities were added together giving a total of 930 minutes/week. This includes an element for travelling time. 
TABLE I

Direct patient contact

(includes para-patient time)

\begin{tabular}{llc}
\hline \multicolumn{1}{c}{ Activity } & $\begin{array}{c}\text { Estimate of time (min) } \\
\text { per occasion } \\
\text { (median of all scores) }\end{array}$ \\
\hline 1. A patient on admission (excluding planned short-term care) & 120 \\
2. Each patient already admitted for treatment or assessment, & 60 \\
3. A new out-patient. Includes referrals from prison, liaison etc. & 105 \\
4. Also includes out-patients seen at home, ATCs etc. & 45 \\
5. A newt-patient on subsequent visits & 55 \\
6. An already admitted day patient & 20 \\
7. A patient admitted for short-term care to relieve the family & 42 \\
8. Each resident of a long-stay ward, each week, one to one & 12 \\
\hline
\end{tabular}

TABLE II

Service information

\begin{tabular}{llc}
\hline & & Median of all scores \\
\hline 1. & Catchment population & 200,000 \\
2. & Total in-patient beds & 120 \\
3. & Acute psychiatric beds & 5 \\
4. & Assessment beds & 3 \\
5. & Rehabilitation beds & 12 \\
6. & Day patient places & 7 \\
7. & Number of out-patients seen per month: & 5 \\
& $\quad$ New & 23 \\
8 & Odeal number of beds for present catchment population & 38 \\
\hline
\end{tabular}

Total medical time: The data from Table II produce a median estimated service with a catchment population of $200,000,120$ in-patient beds, seven day-patients, five new out-patients and 23 old out-patients a month.

The routine medical time required excluding admissions and emergencies is estimated as:

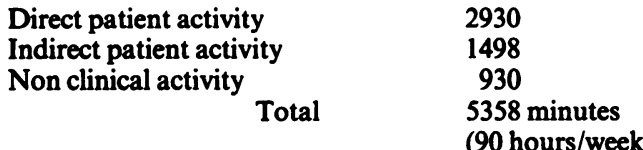

\section{Comment}

The figures arrived at in this survey are not definitions of good practice. The sample of consultants was neither random nor selected by weighted factors and the estimates can be no more than indicators of professional view about certain tasks.
The amount of time estimated is not the total that is required within the practice of mental handicap. Areas not covered in this survey and commented on by the respondents include: time given to emergencies, time given to acute admissions, psychotherapy, (both group and individual), parent groups, forensic needs.

It is striking that the replies demonstrate a wide range of practice among the respondents; this is particularly seen in the service information. The catchment areas range from 44,000 to 600,000 and the number of in-patient beds ranges from 0 to 300 , with little correlation between these.

When looking at estimates of clinical time arising from direct patient contact there is closer agreement: for example, the overall time required for a new outpatient was assessed as from one to three hours. Half the respondents suggested two hours for an outpatient although there were differences in the allocation between face to face and para-patient activity. 
These differences might reflect the wide range of people being seen in these services.

Forty-six per cent of the respondents provide children's services and the assessment procedure of a multiple handicapped child differs greatly from that of a mildly handicapped adult with a mental illness: both require time with the patient and liaison with others, but to differing amounts.

The replies on indirect clinical activity arising from discussion with others also show great variation which appears to reflect the different patterns of service, e.g. the smaller the hospital component the greater the need for liaison in community settings.

The amount of work with long-stay hospital inpatients varies between services and the time estimated for this group of 12 minutes per patient a week appears quite high and probably reflects the increasing dependency and biological abnormality in the group now remaining in hospital. This work is principally primary care and is increasingly being undertaken by non-training grades and interested GPs.

The relocation of these patients into non-hospital community services will not decrease the amount of medical time they need and while general practitioners could take on much of the primary health care of these people in the community, there must be concerns about the necessary degree of ongoing medical surveillance they will receive (Howells, 1986). Those GPs working within hospitals build up a considerable amount of experience in this unusual field and it is unlikely that the average GP will develop the same expertise.

It is possible to differentiate the estimates of clinical time (direct and indirect) into hospital and community components: (hospital 3118 minutes, community 1310 minutes). Taking away the time estimated for the long-stay patients reduces the hospital component to 1918 minutes producing a hospital to community ratio of 60 to 40 , which may represent the current average split for specialist psychiatric work.

There are major dilemmas for specialists in this field, for as the number of people being resettled increases and as the number of people being admitted decreases it seems apparent that there will need to be an increase in medical time within the community settings; however, as the hospitals decline the need for planning the contraction and movement of patients within them may increase the demands on consultant time and these changes may lead to greater disturbance within the residents with consequent need for greater medical support.

If the calculations applied to the median estimates, as described in the results, are applied to each completed questionnaire then an amount of medical time can be estimated for each. There is a wide range of results; however, the medical time bears a greater relationship to the number of hospital beds than to the size of the district.

This tying of medical time to beds may be interpreted as before with regard to the high level of pathology in the residual hospital population, but it is also important to consider if the speciality is seeing itself too bound up with beds and not sufficiently developing its consultant role within the community.

The long-term need for psychiatric beds was addressed by asking the respondents what they viewed as the ideal number of beds for their service. There is again a wide range of views, from two to 130 beds being suggested. Taking catchment size, this represents 0.006 to 0.65 beds per 1000 population. These estimates again appear related to the number of in-patient beds already in the service and suggest that services are planned according to what is familiar.

The median number of beds ideally required is 38 (includes admission, and rehabilitation beds) and in the estimated district of 200,000 this represents 0.19 beds per 1000 population.

This is in a similar order to the figure of 0.25 beds per 1000 population which has been suggested by Day (1983). This figure also appears in recent College papers outlining the recommended shape of services (The Royal College of Psychiatrists, 1985, 1986).

In the estimated service produced by the median scores, if 20 hours of medical time is given to primary care then approximately $\mathbf{7 0}$ hours are left for specialist medical care. In keeping with Achieving $a$ Balance' (DHSS, 1986) this specialist care should be delivered where possible by a consultant and training posts should be carefully matched to consultant numbers.

As discussed earlier, the median estimate does not include a number of important activities - therefore the specialist input of two consultants would be the minimum required. This would give a requirement of one consultant per 100,000 population, the current minimum being one per 200,000 (The Royal College of Psychiatrists, 1985).

Given an approximate job occupancy of 25 years as a consultant and four years in each training grade, there would need to be one registrar and one senior registrar to every six consultants. The senior registrar should be counted as supernumerary. The registrar would contribute 20 hours clinical time (Watson, 1986) and could take a role in some of the primary care.

A further consideration for primary care is that those non training grade doctors who have developed expertise in this area within the hospitals should consider moving into community based jobs such as SCMO/clinical assistant, to support and complement the general practitioners. However, it is important to recognise that the results of this survey 
forecast a sizeable number of in-patient beds which will require 24 hour cover.

Taking a population of 600,000 people, the future medical service suggested by this survey would be two non-training doctors, a registrar, a senior registrar and six consultants with 114 in-patient beds.

The discussion has tried to draw inference from the summation of data of great variance rather than trying to explain the variance. Accepting this the results of this survey create an estimated current service with a catchment population of $200,000,120$ inpatient beds and a need for 90 hours of medical time.

While there is reasonable agreement on time spent over clinical assessment, there is a great variation in catchment population, in present in-patient beds and the predicted number of beds required in the future. The estimated need for medical time appears more closely related to bed numbers than to community population; this may be explained by the high level of pathology in the residual hospital population. There is a need to consider the primary medical services in the resettlement of such residents.

It is suggested that the medical time of 90 hours is split between two consultants supported by SCMOs/ clinical assistants or by trainees. This would require an increase in the consultant establishment from 1 to 200,000 population to 1 to 100,000 .

\section{Acknowledgement}

I would like to thank those who took part in this study and, also Professor J. Watson and Professor R. Priest for their advice.

\section{References}

DAY, K. A. (1983) A hospital based psychiatric unit for mentally handicapped adults. Mental Handicap, 11, $137-140$.

DHSS (1986) Achieving a Balance. London: DHSS.

HowelLS, G. (1986) Are the medical needs of mentally handicapped adults being met? Journal of the Royal College of General Practitioners, 36, 449-453.

ROYAL COLLEGE OF PSYCHIATRISTS (1985) Guidelines for regional advisers on consultant psychiatrist posts in mental handicap. Bulletin of The Royal College of Psychiatrists, 9, 207-208.

(1986) Psychiatric services for mentally handicapped adults and young people. Bulletin of The Royal College of Psychiatrists, 10, 321-322.

WATSON, J. P. (1986) Calculating a district's psychiatric manpower. Bulletin of The Royal College of Psychiatrists, 10, 334-337.

\begin{abstract}
"Conferences need to be understood. Some, of course, are purely recreational. Men and sometimes women gather at the expense of a cooperation or foundation. The purpose is free or tax-paid enjoyment. The justification is the exchange of ideas and the value of this is fiercely proclaimed. It is very difficult to say in criticism of such a conference that no ideas were exchanged.

of serious conferences, very few are to exchange information and fewer still to reach decisions. Most are to proclaim shared purposes, to reveal to the participants that they are not alone and thus reinforce confidence. Or they are to stimulate action where action is impossible. By acting, they persuade the participants, and of ten others, that something is happening when nothing is happening or can happen."
\end{abstract}

\title{
J. K. Galbraith
}

